reddish brown, but some are black. Dr. Germaine A. Joplin, of the University of Sydney, has given a series of igneous rocks described by her, and rocks described in the Records of the Geological Survey of New South Wales are a donation from the Curator of the Mining and Geological Museum, Sydney. Dr. K. S. Sandford has presented the series of rocks which he collected when with Major Bagnold's expedition in 1932 and has since described. An opaque crystal of scheelite from Perak, larger than any hitherto in the Museum, has been given by $\mathrm{Mr}$. John Weekley. Of considerable historical interest is the diary kept by Robert Allan (1806-63) during a visit to the Mediterranean in 1830 , which has been given by Miss B. M. Clay, one of his descendants. Robert Allan was the son of Thomas Allan (17771833), the Edinburgh banker, whose mineral collection was bought after his death by R. H. Greg and acquired by the British Museum in 1860. Many of the minerals and rocks collected during this expedition are in the Mineral Department.

The Department of Botany has received 1,650 plants collected by Messrs. G. Sherriff and F. Ludlow in Bhutan and Tibet. The route followed was from the Assam plains near Gauhati, through eastern Bhutan. Tibet was entered up the Nyan Jang Chu, a river rising north of the main Himalayan range which cuts its way through the range and flows south to join the Manas River. The plateau region was crossed and one of the headwaters of the Subansiri River was followed down. There six months were spent with Tsari as a centre, an area which proved very rich in alpine flora, some of the grassy hill-sides, above the tree-line, being literally covered with Primulas. After the flowering season was over, seeds were collected. It is probable that several interesting horticultural plants will be introduced to British gardens, for a number of new species of Primula and a new Mecanoxsis were found. The specimens are exceedingly well preserved and the collection is a most valuable addition to the series of Himalayan plants in the Department. Among purchases are 600 flowering plants from the west-central district, Sikang, of China, the first consignment of a set of Dr. Harry Smith's collections on his recent expedition; the herbarium of A. L. Hübl, containing 4,600 specimens chiefly from Austria, and the moss herbarium of the well-known Dutch bryologist Fr. Verdoorn, comprising about 3,200 specimens.

\section{Alcohol and Motor Accidents}

AT a meeting of the Society for the Study of Inebriety on January 12 reported in the British Medical Journal of January 23, Dr. H. M. Vernon stated that though the maximum of road traffic accidents during the last two years was a little less than in 1934, the fatalities still averaged 18 a day and the injuries more than 600. Half the deaths were among pedestrians and a fifth among pedal cyclists, while drivers of motor vehicles and their passengers had only a third to a fourth as many accidents as pedestrians. Although the data of the
Ministry of Transport indicate that only 1 in 80 of the road fatalities are due to persons obviously under the influence of drink, the evidence from America suggests that alcohol plays a much larger part in motor accidents. Alcohol even in moderate quantities frequently affects driving capacity, and in particular causes drivers unconsciously to increase their speed, which is the most important factor in the causation of fatal accidents. Examination of the blood or urine by Widmark's method shows the following correspondence between the alcohol content and the clinical symptoms. In persons with 1 part of alcohol per 1000 in the blood, 40-60 per cent were found to be "under the influence"; of those with $1 \cdot 7$ parts, 80-88 per cent were so affected, and of those with 2 parts all were affected. Dr. Vernon has come to the conclusion that abstinence from alcohol should be practised for several hours before driving as well as during its course, as the rate of disappearance of alcohol from the blood is very slow.

\section{Communal Aerials for Radio Reception}

IN large towns and cities, the provision of a good aerial generally presents many difficulties, especially in houses divided up into self-contained flats. In the latter case, it would be necessary to erect on one roof a number of separate aerials which would satisfy the varying requirements of the listeners. In some places also there is an almost insuperable difficulty owing to interference from electric motors and other electric devices. Some years ago the Philips Research Laboratories at Eindhoven, Holland, evolved a communal aerial system which they call the 'Antennaphil' which surmounts most of the difficulties met with in practice. A description of it is given in the Journal of the Philips Research Laboratories of August last. In this system an aerial of suitable dimensions is erected at a spot where interference is limited, for example, at a height of twenty feet above the roof. Through a specially screened conductor made as short as possible, the aerial is connected to an aerial signal amplifier, from which the incoming signals are transmitted to a number of receiving sets through a lead-covered cable which acts as a screened distributing circuit. Up to fifty sets can be connected to an aerial fitted with this form of amplifier. If the distance of the spot from which reception, practically free from interference, can be received is a few hundred yards, then the number of sets is less. But even up to a distance of 1,000 yards, several sets can be supplied. An aerial of this type has been in use at the laboratory for several years at a distance of 200 yards, and has ensured reception free from all interference. It is proved that a concentric cable of suitable dimensions is the best to use for high-frequency distribution.

\section{"For Intellectual Liberty"}

The Society "For Intellectual Liberty", which was founded early in 1936 as a rallying-point for intellectual workers concerned with the active defence of peace, liberty and culture in the present conditions of the world, has recently issued its first bulletin. 